\title{
Argentaffin and non-argentaffin carcinoid tumours of the appendix
}

\author{
F. E. DISCHE
}

From Dulwich Hospital Pathology Department (King's College Hospital), London

SYNOPSIS Tumours of the vermiform appendix were studied. The majority proved to be carcinoid tumours of the usual argentaffin-positive type but a substantial minority, generally tumours? of minute size, were found to have a somewhat different histological pattern and were argentaffin-.negative. Some contained argyrophil granules. The non-argentaffin tumours are considered to form a subgroup of carcinoid tumours.

The carcinoid tumour of the appendix is usually regarded as an archetype of the argentaffin-positive carcinoid. After coming across an unusual argentaffin-negative tumour I was prompted to make a special search for tumours in a large series of appendices and the results of this investigation are given below.

\section{MATERIALS AND METHODS}

The specimens examined consisted of 1,426 consecutive surgically-removed appendices received in this department and included normal as well as pathological material. After fixation in $10 \%$ formol-saline the terminal $1.5 \mathrm{~cm}$. was bisected longitudinally and both halves were imbedded in paraffin wax. Sections were also taken from other sites when indicated. Tumours were found in 19 instances (series A). A second group of 14 appendix tumours, which had been encountered in ordinary routine work mainly at King's College Hospital, was also examined for comparison (series B).

Standard staining methods were used, similar to or slightly modified from those of Culling (1963). Enterochromaffin granules were identified by the MassonFontana ammoniacal silver method and by the alkaline diazo method using fast red salt B. I am indebted to Dr. Ian Dawson for details of a modified Bodian's protargol method for argyrophil granules.

\section{RESULTS}

Marked differences were found between the two series. The series A tumours were small and were rarely pigmented and only about half were argentaffin-positive. In series B the tumours were larger and were mostly yellow and all but two were argentaffin-positive. For descriptive purposes the

\footnotetext{
Received for publication 16 May 1967.
}

material has been pooled and divided into two groups based on the argentaffin reaction (for convenience the term argentaffin is used to cover ${ }^{\gtrless}$ also the diazo reaction). The salient findings are $\vec{\varnothing}$ summarized in Table I.

TABLE I

COMPARISON OF ARGENTAFFIN AND NON-ARGENTAFFIN TUMOURS

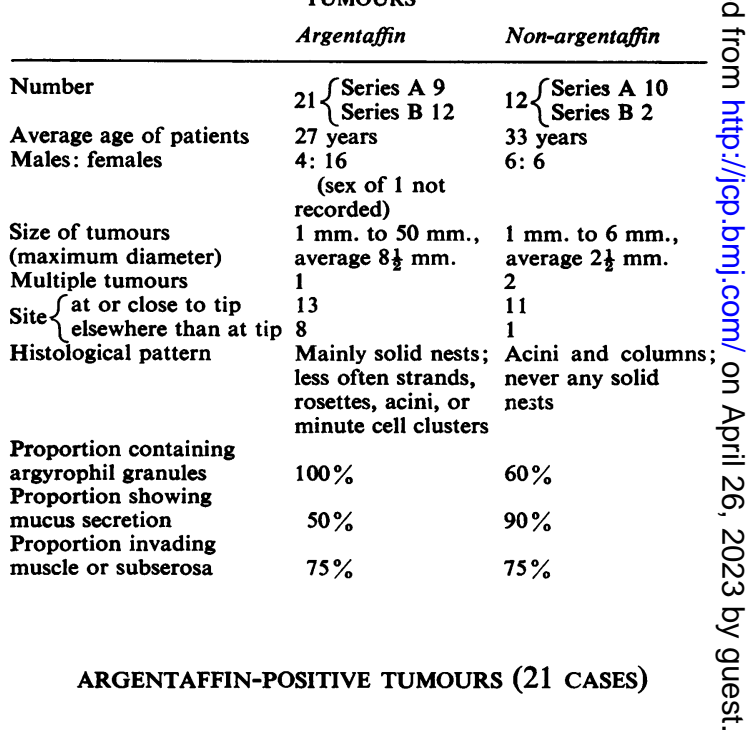

These varied in size from $1 \mathrm{~mm}$. upwards and 0 averaged $8 \frac{1}{2} \mathrm{~mm}$. in diameter. Rather more than $\frac{\mathrm{O}}{\mathbb{P}}$ half were situated at the tip of the appendix. Most $\stackrel{\mathbb{D}}{\stackrel{\circ}{\circ}}$ were distinctly yellow in the formalin-fixed state $\stackrel{\mathbb{Q}}{\circ}$ and the pigment was well preserved in paraffin- 
embedded material. The few that showed no special colour were small and might have been missed on naked-eye inspection.

Histological PICTURE Two main types of structure were seen, a solid type and a glandular type. The solid type was characterized by cell nests which were round or oval (Fig. 1) but which were sometimes reduced to narrow cords, particularly where they infiltrated the muscle layers. The tumour cells were closely packed and fairly uniform with spherical or oval nuclei (Fig. 2). Mitotic figures were scanty. The cytoplasm contained fine eosinophilic granules which were most numerous at the periphery of the cell masses and which gave positive argentaffin, diazo and argyrophil reactions. Sometimes the cell nests were surrounded by a palisade layer of tall columnar cells (Fig. 2). In other instances the peripheral cells had basally situated nuclei (Fig. 3) and this seems to be a step towards glandular differentiation; neoplasms with this form exhibited marked cytoplasmic vacuolation (Fig. 3), whereas with other types of structure vacuolation was a variable feature.

A glandular pattern was shown by the presence of small blind acini (Fig. 4), which often contained inspissated mucinous secretion, or of solid rosettes without a lumen and usually composed of large pale vacuolated cells. Rosettes were more numerous than acini. It is thus possible to trace a series of steps in glandular differentiation from simple solid foci to solid foci with basal peripheral nuclei, to rosettes, and finally to acini. In glandular areas the argentaffin granules were largely confined to the basal zone.

The stroma varied in amount and was sometimes scanty. It consisted of collagen and some elastic fibres and often incorporated hypertrophied smooth muscle. Most of the tumours had invaded the muscle coats and some the serosa but none had spread beyond the appendix.

The tumours were composed of mixtures of solid and glandular elements, giving a spectrum from the completely solid to the completely glandular. The solid pattern, however, was much the commonest feature and few lacked it completely. The exceptions included one tumour which was composed exclusively of small non-vacuolated acini with a pattern closely similar to that of some of the nonargentaffin tumours to be described (Fig. 5). Another differed from all the rest and consisted only of irregular-shaped cell clusters of minute size scattered in a stroma composed of hypertrophied muscle (Fig. 6). It contained small numbers of granules which were weakly diazo-positive but which were negative to the argentaffin reaction

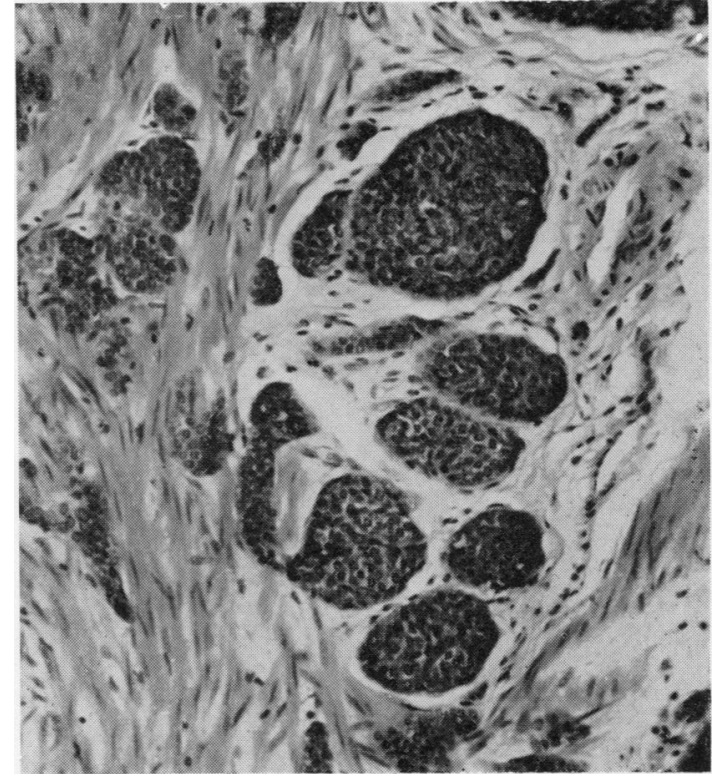

FIG. 1. Argentaffin-positive tumour: Solid cell nests. Haematoxylin and eosin $\times 140$.

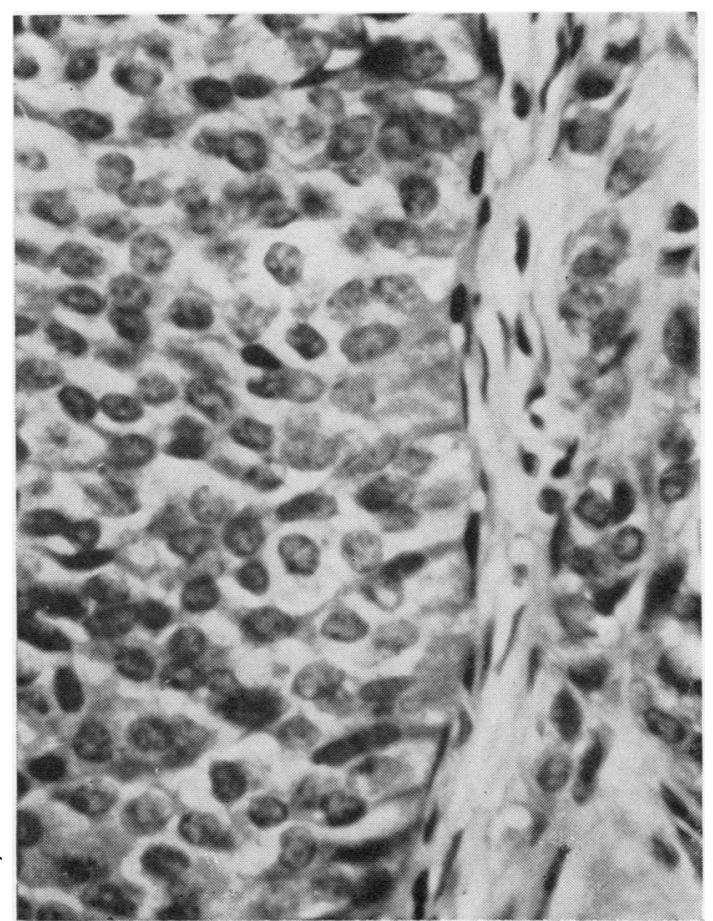

FIG. 2. Argentaffin-positive tumour: palisade layer of tall columnar cells around a cell mass; uniform tumour cell nuclei. Haematoxylin and eosin $\times 550$. 


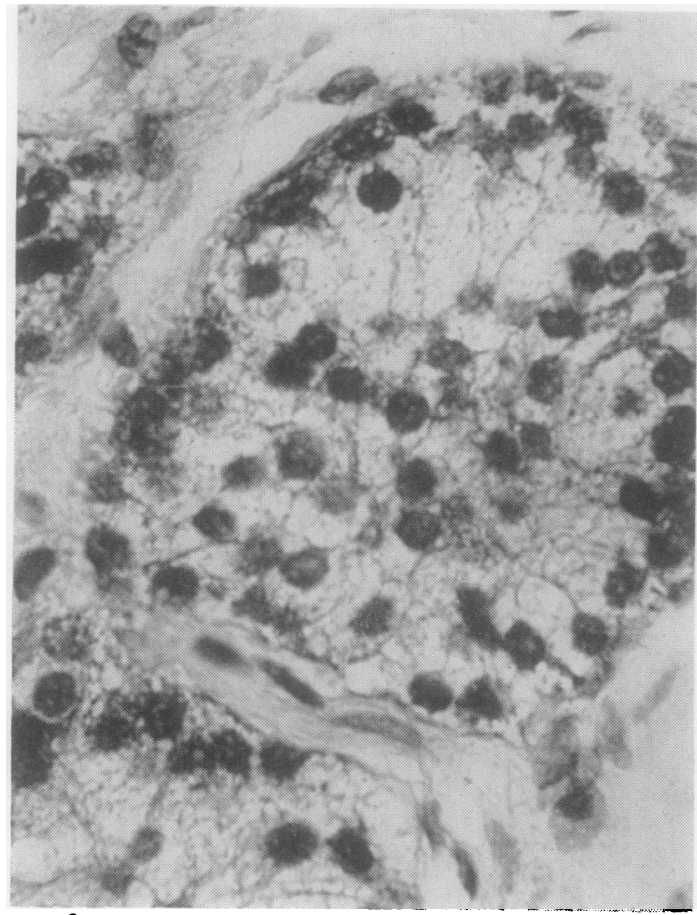

FIG. 3.
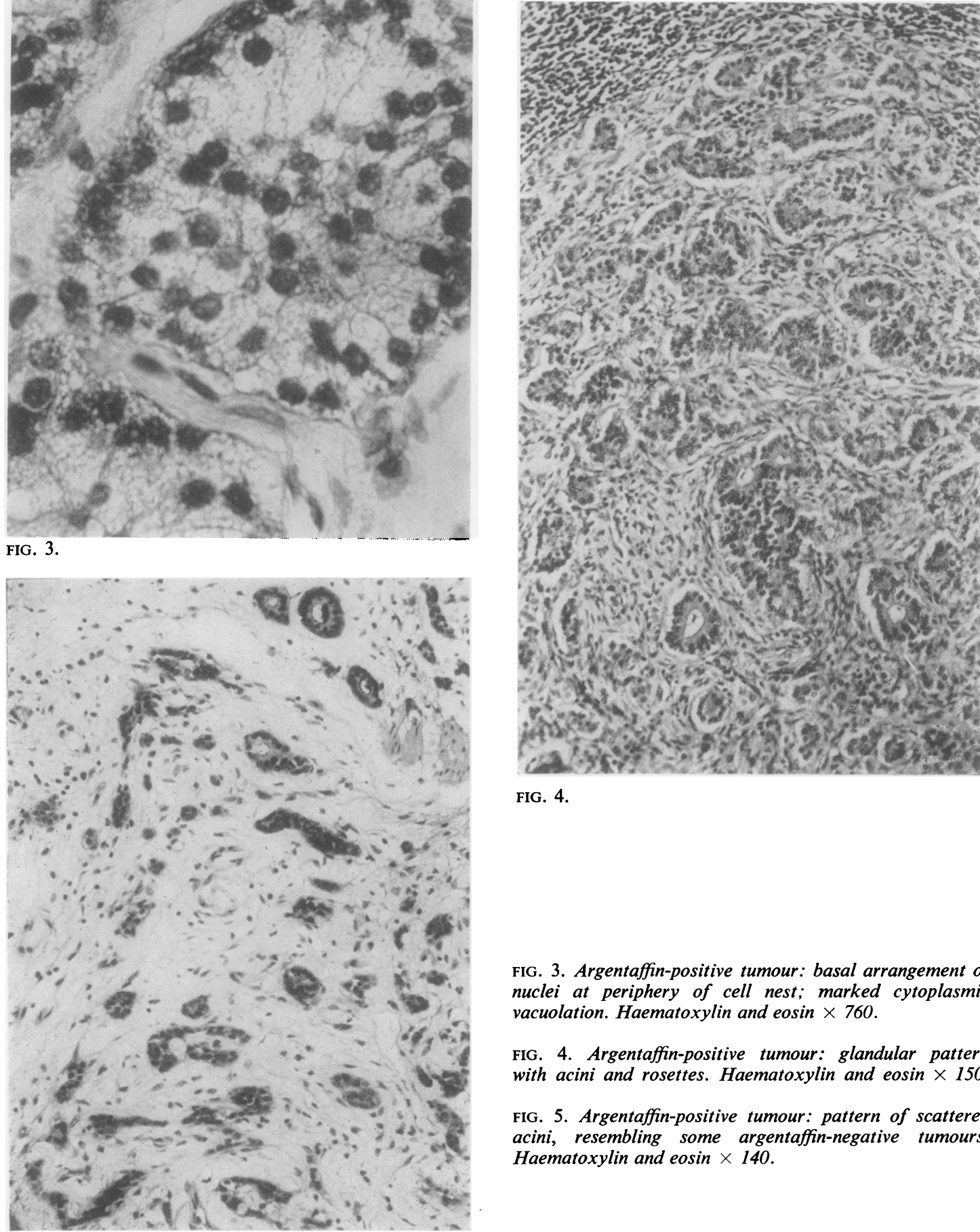

FIG. 4.

FIG. 3. Argentaffin-positive tumour: basal arrangement of $\mathrm{N}$ nuclei at periphery of cell nest; marked cytoplasmic $ᄋ$ vacuolation. Haematoxylin and eosin $\times 760$.

FIG. 4. Argentaffin-positive tumour: glandular patterno with acini and rosettes. Haematoxylin and eosin $\times 150 . \stackrel{\mathbb{D}}{\circ}$

FIG. 5. Argentaffin-positive tumour: pattern of scattered acini, resembling some argentaffin-negative tumours. $\overline{0}$ Haematoxylin and eosin $\times 140$.

FIG. 5 . 


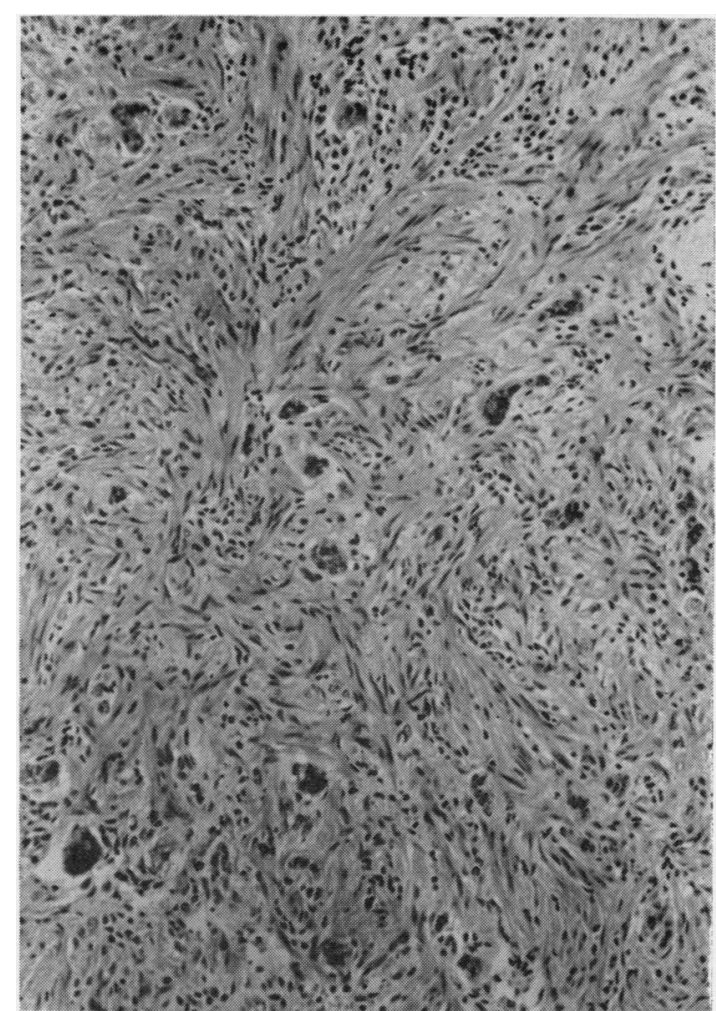

FIG. 6. Argentaffin-positive tumour: unusual pattern of minute cell clusters. Haematoxylin and eosin $\times 140$.

proper. This tumour too shows affinities with the non-argentaffin group.

\section{ARGENTAFFIN-NEGATIVE TUMOURS (12 CASES)}

These were remarkable for their small size, the largest being only $6 \mathrm{~mm}$. in diameter. None possessed any distinctive colour and as a result they were practically invisible to the naked eye, all being first detected only on microscopy. All but one were found in appendices which were either inflamed or fibrotic. Most were at the tip, commonly in an axial position, while in two instances further sectioning revealed a second tumour which was similar in structure to the first.

Histological PICTURE The tumours were composed of glandular acini and solid cell columns. The acini (Fig. 7) were small, sometimes extremely so, and often asymmetrical and the narrow lumen usually contained secretion (Fig. 8). Small rosettes were occasionally seen. The columns were usually only 1 or 2 cells wide. They were short (Fig. 9) or occasionally longer and somewhat twisted (Fig. 10) but in only one case did the degree of twisting approach that commonly found in carcinoid tumours of the rectum (Fig. 11). Nearly all the tumours were composed of mixtures of glands and columns and often a column was joined to a gland (Fig. 8). One neoplasm was formed exclusively of columns. Round solid nests typical of the argentaffinpositive tumours were never seen.

Most of the tumours appeared to originate at the periphery of the mucosa, where groups of neoplastic cells could be found around the tips of the glands (Fig. 9). In two instances direct contact and possible continuity between neoplastic cells and non-neoplastic glands were seen, but no special relationship to normal enterochromaffin cells could be made out. Infiltration of the mucosa was always confined to the rim but invasion outwards was common, although extension did not occur beyond the outer limits of the muscle coats. The stroma consisted of collagen and a few elastic fibres and frequently included hypertrophied muscle. It was comparatively plentiful and the neoplastic elements were often rather scattered.

The tumour cells were small and the nuclei were round, oval, elongated or irregular-shaped and tended to stain deeply (Fig. 8). No mitoses were ever found. The cytoplasm sometimes contained a few small vacuoles. No eosinophilic or argentaffin granules could be demonstrated despite adequate 'control' staining of normal enterochromaffin cells which were present in the same section in nearly every case. Localized deeply eosinophilic areas were often seen in the cytoplasm but these were non-granular and argentaffin-negative. Positive results were obtained, however, with Bodian's argyrophil method: six of the 10 tumours examined contained variable numbers of red, brown, or black argyrophil granules, which were usually extremely fine and arranged in tight clusters (Fig. 12) but occasionally coarser and more scattered. In the acini they were basally situated. The granules could be demonstrated only when impregnation of the normal enterochromaffin cells was strong and it was inferred that the reaction in the tumour was a weak one.

MUCIN SECRETION The periodic acid-Schiff reaction and Southgate's mucicarmine were used to demonstrate mucin. Nine of 18 argentaffin-positive tumours and nine of 10 argentaffin-negative tumours examined contained positively-reacting material. This was largely confined to acini and occasional rosettes, hence the high incidence in the nonargentaffin neoplasms 
FIG. 7. Argentaffin-negative tumour: acinar pattern. Haematoxylin and eosin $\times 140$.

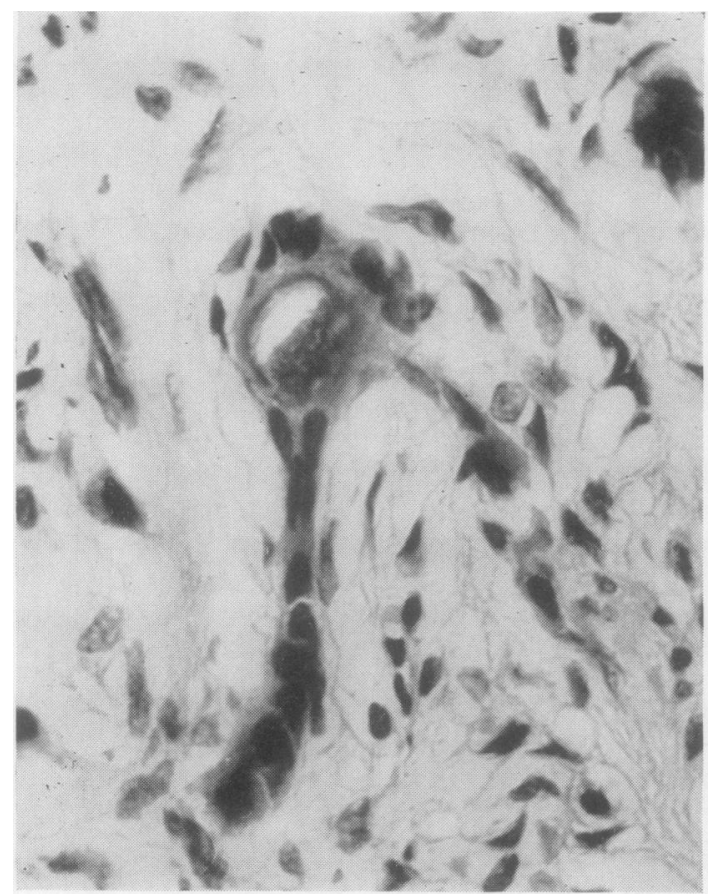

FIG. 8. Argentaffin-negative tumour: asymmetrical acinus containing secretion, continuous with a cell column. Irregular-shaped or elongated dark-staining nuclei. Haematoxylin and eosin $\times 760$.

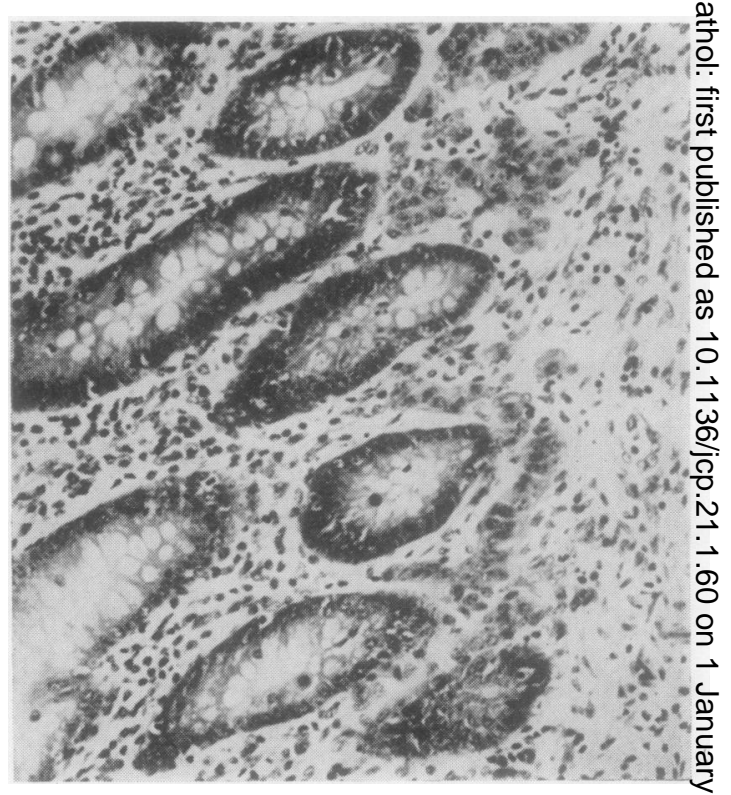

FIG. 9. Argentaffin-negative tumour: short cell columns in $\vec{\varphi}$ periphery of mucosa (same tumour as in Fig. 7). Haema-00 toxylin and eosin $\times 180$.

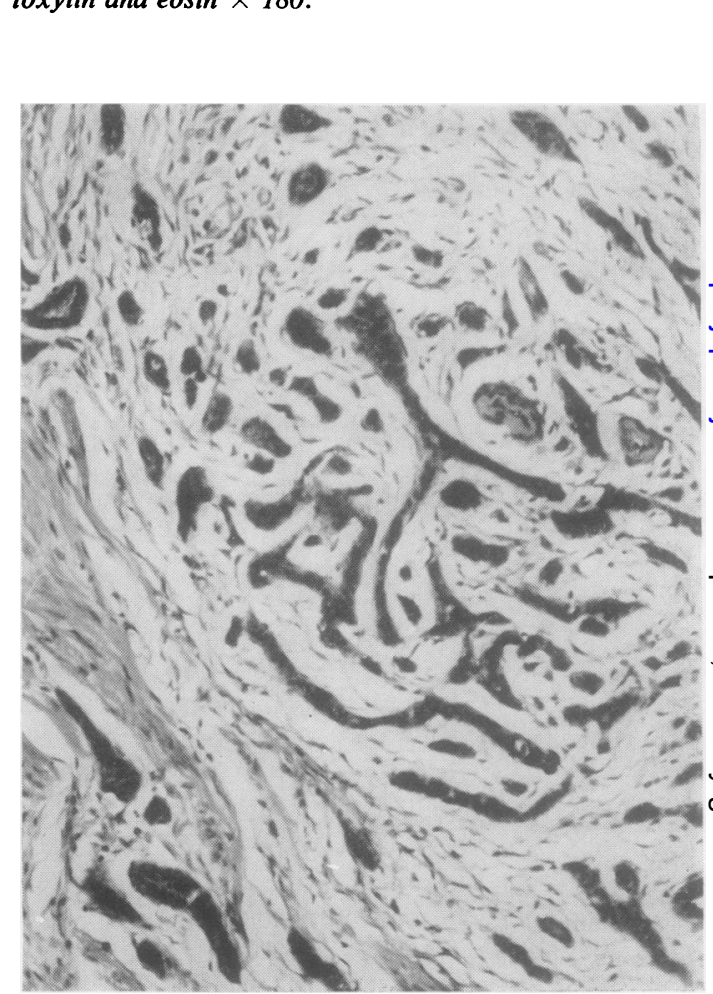

FIG. 10. Argentaffin-negative tumour: longer cell strands. Haematoxylin and eosin $\times 140$. 


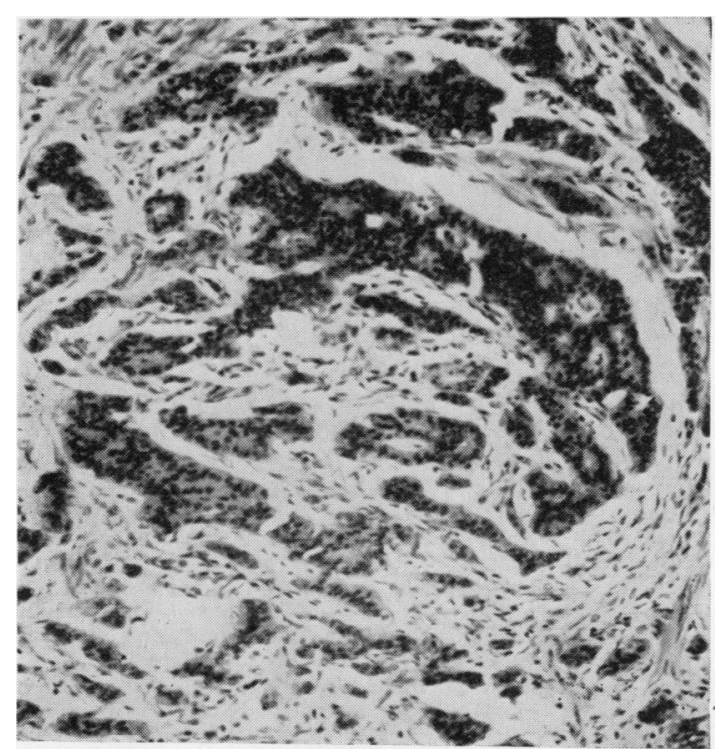

FIG. 11. Argentaffin-negative tumour: twisted cell columns with some resemblance to non-argentaffin tumours of rectum. Haematoxylin and eosin $\times 140$.

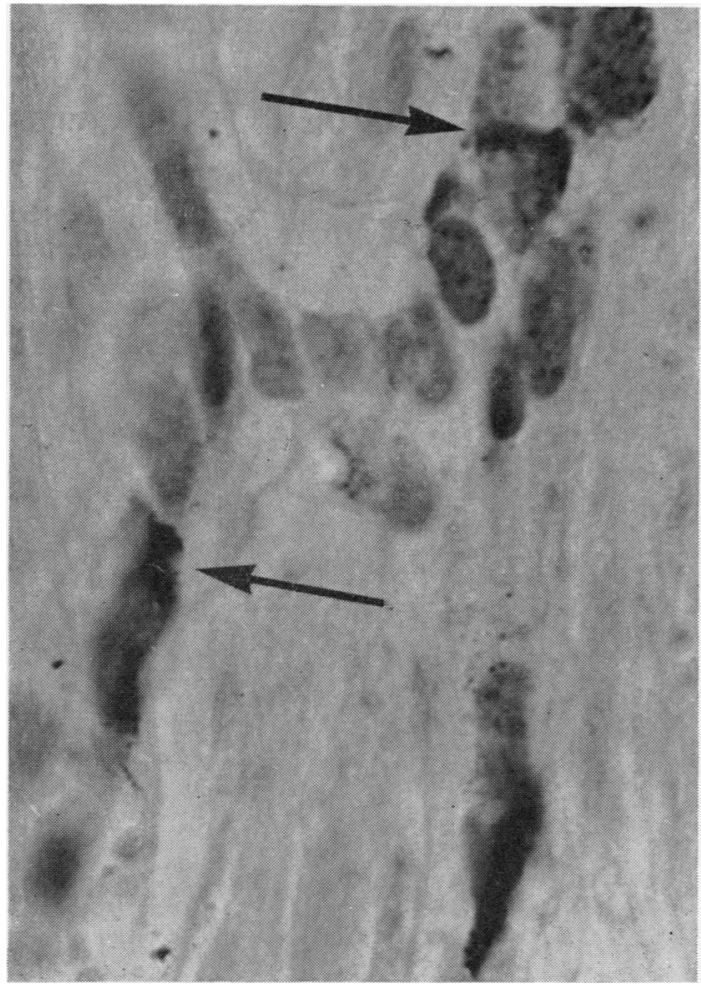

FIG. 12. Argentaffin-negative tumour: argyrophil granules in dense clusters (arrows). Bodian $\times 1250$.
INCIDENCE The overall incidence of the series A tumours in the material from which they were drawn was $1.3 \%$ and the ages of the patients ranged from 10 years to 66 years. The age distribution was similar in the argentaffin and nonargentaffin varieties and was roughly parallel with that of a sample of the case material as a whole.

The sex distribution shows interesting differences. The argentaffin-positive tumours occurred predominantly in females, as is the experience of others (Cooke, 1931), while the argentaffin-negative tumours occurred equally in the two sexes. The difference is suggestive although not statistically significant.

\section{DISCUSSION}

The argentaffin-positive tumours seen in this study were mainly yellow and had a histological structure characterized by the presence of solid cell nests. They were similar to carcinoid tumours described previously (Oberndorfer, 1907; Gosset and Masson, 1914; Masson, 1928; Cooke, 1931; Dockerty and Ashburn, 1943). The argentaffin-negative tumours were smaller, lacked a distinctive colour, and had a predominantly glandular structure. In histological pattern, the argentaffin-negative tumours differed from the argentaffin-positive mainly in the smaller size of their cell formations and the absence of solid nests. The sex distribution probably also differed.

Are the non-argentaffin tumours true carcinoids? The difficulty in answering this question lies in finding a satisfactory definition for the carcinoid tumour. According to Azzopardi and Pollock (1963), argentaffin granules may occur in tumours which are undoubtedly carcinomas rather than carcinoids, while other neoplasms have been considered acceptable as carcinoids despite a negative argentaffin or even argyrophil reaction. The staining reactions are therefore not of overriding importance and regard must be taken of other morphological features and of the rate of growth. The nonargentaffin tumours are undoubtedly slow growing despite their invasiveness and show other resemblances to the argentaffin group. There are similarities in histological pattern as far as glandular structures are concerned and both types are able to cause hypertrophy of muscle in their stroma. The age range is also similar. The evidence therefore suggests that while two groups of tumours are distinguishable they are related and overlap a little. This conclusion is supported by the presence in some nonargentaffin tumours of argyrophil granules, which although less specific than argentaffin granules are regarded by some as evidence in favour of a diag- 
nosis of carcinoid (Pearse, 1960). It therefore appears legitimate to regard all the neoplasms under consideration as 'carcinoid tumours' and to qualify them as 'argentaffin' (or 'argentaffin-positive') and 'non-argentaffin' (or 'argentaffin-negative') carcinoid tumours respectively.

Non-argentaffin carcinoid tumours are known to occur in the rectum (Stout, 1942), the stomach (Lattes and Grossi, 1956), and elsewhere, but there have been few adequately documented reports of such tumours in the appendix or ileo-caecal region. Lillie and Glenner (1960) rejected all but a few on technical grounds. They accepted two cases described by Hasegawa (1923) and two mentioned only briefly by Masson (1924) and added one of their own. Hasegawa's cases, however, were examined after death and it is known that the argentaffin reaction is lost a few hours after death. Lillie and Glenner's caecal tumour was undoubtedly nonargentaffin but no histological description was given. A survey of the literature published since then has failed to bring to light further cases. If the present experience is representative, non-argentaffin tumours should be by no means uncommon: many must have been missed owing to their small size and lack of a distinguishing colour. It is interesting that some of the appendix tumours show resemblances to the carcinoid tumours of the rectum. They differ from these, however, in the smaller size of their cells and the lesser tendency to ribbon formation.

The tumour incidence of $1.3 \%$ reported here is greater than the highest previously recorded by others, namely $0.996 \%$ (Kieraldo, Eversole, and Allen, 1963), 0.689\% (Collins, 1963), and 0.5\%
(Dockerty, 1963). This result is attributable to routine sectioning of the tip of the appendix in $a$. longitudinal plane, which would appear to offe $\overrightarrow{5}$ advantages over transverse sectioning for the detection of minute tumours in the axial portion where they commonly occur.

I am grateful to the late Professor H. A. Magnus fo $\mathbb{B}$ access to material and for advice on the manuscript and to Mr. M. P. Curwen for help with the statistics; als 8 to Mr. James Mason, Mrs. Jean Oxbrow, Mrs. Audrey Wedge, and Mrs. Linda Harte for technical assistance 2 and to Mr. Walter Day and Mrs. Shirley Davis foE photographic and secretarial help respectively.

\section{REFERENCES}

Azzopardi, J. G., and Pollock, D. J. (1963). J. Path. Bact., 86, 443Collins, D. C. (1963). Amer. J. Proctol., 14, 365.

Cooke, H. H. (1931). Arch. Surg., 22, 568.

Culling, C. F. A. (1963). Handbook of Histopathological Technique (Including Museum Technique), 2nd. ed. Butterworth, London. Dockerty, M. B. (1963). Calif. Med., 99, 157. and Ashburn, F. S. (1943). Arch. Surg., 47, 221.

Gosset, A., and Masson, P. (1914). Presse méd., 22, 237.

Hasegawa, T. (1923). Virchows Arch. path. Anat., 244, 8.

Kieraldo, J., Eversole, S., and Allen, R. (1963). Calif. Med., 99, 16 है

Lattes, R., and Grossi, C. (1956). Cancer (Philad.), 9, 698.

Lillie, R. D., and Glenner, G. G. (1960). Amer. J. Path., 36, 623. Masson, P. (1924). Ann. Anat. path., 1, 3. (1928). Amer. J. Path., 4, 181.

Oberndorfer, S. (1907). Frankfurt. Z. Path., 1, 426.

Pearse, A. G. E. (1960). Histochemistry, Theoretical and Applied 2nd ed., p. 642. Churchill, London.

Stout, A. P. (1942). Amer. J. Path., 18, 993.

\section{ADDENDUM}

Since the preparation of this report, 10 further tumours of the appendix have been encountered은 bringing the total in the prospective series to 29 ? Of these, 18 were argentaffin-positive and 11 were argentaffin-negative. 